\title{
LA INMIGRACIÓN Y LOS PARTIDOS POLÍTICOS EN ESPAÑA
}

\section{THE INMIGRATION AND THE POLITICAL PARTIES IN SPAIN}

\author{
Antonio López Álvarez \\ Universidad CEU Cardenal Herrera, Elche. España/Spain \\ anloalva@uchceu.es
}

Recibido/Received: 11/08/2014

Modificado/Modified: 21/08/2014

Aceptado/Accepted: 30/09/2014

\section{RESUMEN}

En el presente trabajo se analiza el fenómeno de la inmigración desde la visión que los agentes políticos y sociales tienen de la misma. En especial, el papel que juegan los partidos políticos y los grupos parlamentarios en la defensa y crítica a las políticas migratorias que se implementan. Para ello, se ha procedido a realizar un breve diagnóstico de la historia reciente de la inmigración en nuestro país y las políticas legislativas en la materia. Para continuar con la exploración de los programas electorales de cuatro partidos de ámbito nacional, con el objetivo de mostrar si la politización de la inmigración y la visión que de la misma tienen los ciudadanos, adquiere sus referentes en los citados programas, o por el contrario, es más una labor de los grupos parlamentarios y medios de comunicación en el día a día.

\section{PALABRAS CLAVE}

Flujos migratorios, grupos parlamentarios, integración, politización programa electoral.

\section{SUMARIO}

1. Introducción. 2. La inmigración en España. 3. Las políticas de inmigración. 4. Partidos Políticos e inmigración. 5. Conclusiones. Bibliografía.

\begin{abstract}
This paper analyses the phenomenon of immigration from the point of view of political and social actors. It particularly deals with the role the political parties and the parliamentary groups play in the defense and criticism of the migration policies that are applied. To reach this aim, a brief diagnosis of the recent immigration history in our country and the legislative policies has been carried out. This has been followed by an analysis of the electoral program of the four national parties, with the aim to show if the politicization of immigration and the citizens' view over the same subject acquires its references in the mentioned programs or on the contrary it is guided daily by the parliamentary groups and means of communication.
\end{abstract}

\section{KEYWORDS}

Migratory flows, parliamentary groups, integration, politicization, electoral program.

\section{CONTENTS}

1. Introduction. 2. The immigration in Spain. 3. Politics of immigration. 4. Political Parties and immigration. 5. Conclusions. References. 


\section{INTRODUCCIÓN}

La constitucionalización de los partidos políticos en España es un hecho relativamente reciente, si nos atenemos al proceso de incorporación de los mismos en Europa, concretado en la etapa de la posguerra y en las constituciones de los Estados sociales y democráticos de Derecho. Este salto cuantitativo en la historia de los partidos políticos, o lo que es los mismo, el paso de la legalización a la constitucionalización, supone un punto de inflexión en la historia de la democracia representativa, y en el caso de nuestro país, aunque con retraso por razones obvias, la primera vez que los mismos se incorporan a un texto constitucional.

Así pues, nuestra norma fundamental en su art. 6, constitucionaliza esta figura, estableciendo las funciones que los partidos políticos ejercen: expresión fundamental del pluralismo político, concurriendo a la formación y manifestación de la voluntad popular como instrumento fundamental de participación política. En definitiva, la herramienta principal de participación política de la ciudadanía, que permite concertar los intereses de la misma constituyéndose en la pieza esencial a través de la cual la representación política se articula. O lo que es lo mismo, son asociaciones privadas con relevancia pública (Álvarez Conde, 2012: 382) cuyo desarrollo constitucional y legislativo exige una estructura y funcionamiento interno democrático, únicamente sometido a los límites que la Constitución y su régimen jurídico propio determinan (Ley 54/1978, de 4 de diciembre, de Partidos Políticos; y Ley Orgánica 6/2002, de 27 de junio, de Partidos Políticos). Estos límites se circunscriben a la libertad de creación y afiliación de partidos, su inscripción en el Registro, la ilicitud de partidos políticos que no respetan los valores y principios democráticos junto con la financiación pública y privada, entre otros.

Por otro lado, la migración de seres humanos de un lugar a otro es un hecho consustancial en la historia de la humanidad, y más aún en un contexto sociopolítico en el que los flujos migratorios involucran a un buen número de países (emisores y receptores), y en el que las causas económicas siguen jugando un papel esencial.

Nuestro país no es una excepción. Pues a los tradicionales flujos migratorios de los países del sur hacía el norte (Reino Unido, Irlanda, Alemania, Italia, Austria, Bélgica, Suiza y Países Bajos) durante siglo XX, ha aparecido una inmigración reciente e intensa en nuestro país, a lo largo de los últimos quince años. Lo que nos sitúa no sólo como país de tránsito sino como país receptor de inmigrantes. Y es aquí, qué duda cabe, donde aparece el nudo gordiano de la inmigración: ¿qué políticas hay que aplicar al fenómeno de la inmigración? ¿Son políticas europeas o nacionales? ¿Qué papel juegan los partidos políticos en el citado fenómeno? ¿Cómo perciben los ciudadanos españoles y los inmigrantes esas políticas?, y por último, si aceptamos la politización de la inmigración por los partidos políticos y estos son los máximos -aunque no únicos- representantes del pluralismo político y de la manifestación popular, podemos colegir que la visión de la inmigración por la ciudadanía está en cierta medida condicionada por las políticas de inmigración que el poder político desarrolla en cada momento. Por ello, el objetivo de este estudio será el de analizar si las mismas están concernidas a la simple gestión del flujo migratorio o dirigidas hacia la integración del inmigrante, y si el respeto de los valores, principios y derechos constitucionales, tienen lugar en los programas electorales de los partidos políticos de ámbito nacional. 


\section{LA INMIGRACIÓN EN ESPAÑ̃}

El fenómeno de la inmigración en España se produce más tarde que en el resto de los países europeos de nuestro entorno. La llegada de nuestro país a la democracia en las últimas décadas del siglo XX, la incorporación del mismo a la Unión Europea, el proceso de crecimiento económico fundamentado en el sector terciario y de la construcción, junto con la situación geográfica de España como puerta de entrada a Europa en el mediterráneo, contribuyó a que las migraciones, que ya se habían producido a largo de la segunda mitad del pasado siglo en gran parte de Europa, tuvieran lugar en nuestro país (Ortega Giménez y López Álvarez, 2011: 130)

Estos flujos migratorios han tenido efectos sobre todos los ámbitos de la vida social y política, al producir cambios en la demografía española y la natalidad, en el mercado laboral, en las relaciones internacionales con los países emisores, y en el ordenamiento jurídico español, lo que sin duda ha revertido en una sociedad más rica y próspera que la que nuestro país tenía unos años atrás, pero también ha repercutido en la utilización política de la inmigración, como fuente de problemas socioeconómicos.

En nuestro país, por los motivos anteriormente señalados, la población extranjera residente ha sufrido un constante ascenso a largo de los últimos treinta años. Ésta evolución se observa en los datos del Instituto Nacional de Estadística. A modo de ejemplo, en el año 1981 la población extranjera era de 542.314 habitantes, lo que suponía un 1,37 \% de la población total, alcanzando su porcentaje máximo en el año 2011 con 5.739 .667 , con un $12,2 \%$ sobre la población total. En los tres últimos años se ha producido un ligero descenso de la inmigración como consecuencia de la consolidación de la crisis económica, siendo el número de extranjeros censados en la actualidad (datos del Instituto Nacional de Estadística a 1 de enero de 2014) de 4.676.022, lo que sitúa en un 10,5\% de la población en España (46.507.760).

Durante este proceso de aumento de los flujos migratorios en España, también se ha de señalar una evolución significativa de la inmigración en los países emisores, siendo Latinoamérica, la Unión Europea, y el Norte de África, el origen de la mayoría de los inmigrantes en España.

En la última década, nuestra sociedad se ha transformado ante un fenómeno novedoso que ya había tenido lugar en gran parte de Europa, que plantea problemas jurídicos, económicos, sociales y culturales, y que merece respuestas correctas en la que están implicados, la ciudadanía y los agentes sociales. Este nuevo escenario ha de ser interpretado en clave geopolítica, ya que no es sólo una circunstancia pasajera, sino algo consustancial a la historia de la humanidad, sobre todo en un mundo globalizado en el que se encuentran implicados los países de origen y de destino, en el que los inmigrantes no son sólo seres humanos desesperados -sin cualificación alguna- por encontrar puesto de trabajo, sino que los motivos que originan la migración obedecen a situaciones de pobreza, qué duda cabe, pero también a la búsqueda de un trabajo en el que puedan desarrollar la cualificación profesional obtenida en los países de destino. La llegada de profesionales comunitarios a nuestro país y la salida de ciudadanos españoles con destino a Europa e Iberoamérica en busca de oportunidades laborales (547.890 españoles salieron de nuestro país en el año 2013) ponen de manifiesto la realidad con la que nos enfrentamos.

Por todo ello, la inmigración en España como fenómeno relativamente reciente, ha de ser abordado en toda su complejidad. Y es esta complejidad la que a mi juicio, en numerosas ocasiones, no es tenida en cuenta por aquellos que tienen la obligación de afrontarla: partidos 
políticos e instituciones públicas. Con frecuencia se aborda la inmigración desde una perspectiva exclusivamente económica, obviando, como ya se ha señalado, que la inmigración obedece a un conjunto de factores en los que la globalización económica, los conflictos internos en los países de origen, la ausencia de democracia en los mismos, o la búsqueda de un mejor proyecto de vida, configuran un fenómeno que no ha de ser residenciado únicamente en elementos económicos y laborales (Martínez de Pisón, 2004:7).

\section{POLÍTICAS DE INMIGRACIÓN}

Siendo la extranjería una competencia del Estado, tal y como se desprende del artículo

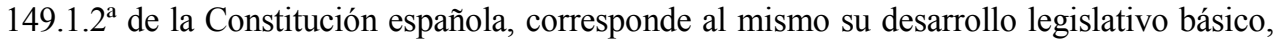
teniendo las Comunidades Autónomas transferidas determinadas competencias en materia de extranjería, tales como la educación, vivienda, sanidad, asistencia social, empleo y cultura.

En nuestra historia reciente como país receptor de inmigrantes, la concreción de una política de inmigración con contenido legislativo nace del mandato constitucional recogido en el artículo 13 de nuestra norma fundamental, al señalar que los extranjeros gozarán de las libertades públicas que los tratados y la ley establezcan. Y esa primera ley de extranjería (Ley Orgánica 7/1985, de 1 de julio sobre derechos y libertades de los extranjeros en España), elaborada meses antes de la incorporación de España a la Comunidad Económica Europea, será una norma restrictiva de derechos, acentuando el control policial y la rigidez en los procedimientos de la obtención de residente, siendo recurrida ante el Tribunal Constitucional y declarando el mismo la inconstitucionalidad parcial de la misma al restringir derechos fundamentales al extranjero (derecho de reunión y asociación).

Unos años más tarde, la evolución del fenómeno migratorio trajo consigo procesos de regularización que no habían podido producirse como consecuencia de la aplicación de la primera ley sobre extranjería, que había dejado a muchos extranjeros en situación ilegal al no poder obtener la documentación necesaria. Estos procesos tuvieron lugar durante los años 1991 a 1996 y derivaron obligatoriamente en el desarrollo de una nueva ley. La Ley Orgánica 4/2000, de 11 de enero, sobre derechos y libertades de los extranjeros en España y su integración social. Desde su aprobación, ha sido reformada en varias ocasiones (Ley Orgánica 8/2000, de 22 de diciembre; Ley Orgánica 11/2003, de 29 de septiembre; y Ley Orgánica 14/2003, de 20 de noviembre), y fue también recurrida ante el Tribunal Constitucional, siendo declarada parcialmente inconstitucional en lo referido a la limitación de ciertos derechos fundamentales a los extranjeros, como el de reunión y manifestación, asociación, y educación.

No será hasta el año 2009 cuando se produzca la última modificación de la ley, con la aparición de la Ley Orgánica 2/2009, de 11 de diciembre, de reforma de la Ley Orgánica, de 11 de enero, sobre derechos y libertades de los extranjeros y su integración social, incorporando la interpretación constitucional sobre determinados derechos anteriormente limitados, y convirtiéndose en la ley actual en materia de extranjería. Ésta ley tendrá su corolario, con la aprobación del Reglamento de Extranjería a través del Real Decreto $557 / 20011$, de 27 de abril, recientemente reformado por el Real Decreto 844/2013, de 31 de octubre (Morales Laura y Ros Virginia, 2012: 7).

La valoración de la política legislativa asociada al incremento de los procesos de regularización durante estos años, ha de ser positiva, sobre todo en lo relativo a lo al reconocimiento de ciertos derechos, como la participación política o la no discriminación de los inmigrantes. 
Aunque la evolución de estas políticas legislativas en los últimos años, está directamente vinculada a las decisiones de la Unión Europea, ésta condiciona las políticas de inmigración llevadas a cabo por los sucesivos gobiernos, tomando como principal referencia la limitación de las fronteras.

En este sentido, será el Acuerdo de Schengen en 1985 el que suprimió las fronteras interiores de los Estados firmantes, estableciéndose acuerdos en materia de mercado laboral, visados, derecho de asilo, controles en las fronteras y cooperación policial y aduanera. El objetivo será el de lograr el acceso de trabajadores comunitarios desarrollándose por vez primera en el Acta Única Europea de 1986, y a través de "Recomendaciones del Consejo" desde el año 1996, y teniendo como corolario el Tratado de Ámsterdam de 1997. Será por tanto, a partir de su entrada en vigor en el año 1999, cuando puede hablarse de una verdadera política de inmigración en el ámbito europeo. El Tratado otorgaba competencias en materia de inmigración a la Unión, compartidas por los Estados miembros, con un objetivo preferente: hacer desparecer el control de ciudadanos comunitarios y no comunitarios en las fronteras interiores de la Unión Europea, durante un período no superior a tres meses.

Será el año 1999 (Consejo Europeo de Tampere) el punto de partida en la coordinación de los flujos migratorios, incorporándose el respeto de los derechos humanos en los desplazados, refugiados, solicitudes de asilo, reagrupación familiar, regulación de la inmigración ilegal y de las condiciones de entrada y salida, todas ellas recogidas en el Programa de Tampere para los años 1999 a 2004, que tuvo su continuidad en el Programa de la Haya (2004 a 2009).

En 2008 el Consejo de la Unión Europea desarrolla con la firma de los países miembros el "Pacto europeo sobre inmigración y asilo", cuyo eje vertebrador será el mercado laboral de los países que necesitan trabajadores inmigrantes para que el crecimiento económico de los mismos y de la propia Unión. Es decir, una política migratoria, en principio respetuosa con los derechos humanos, pero condicionada y sometida a las necesidades del mercado de trabajo de los países miembros.

La continuación de los Programas de Tampere y de La Haya tuvo lugar en 2009, adoptando el Consejo el Programa de Estocolmo, entendido como programa plurianual dedicado a las medidas en el ámbito de la libertad, la seguridad, justicia, y respeto de los derechos humamos, incluidas las prioridades de la UE en materia de política migratoria, durante el período 2010-2014. Todo ello bajo el influjo del Tratado de Lisboa (2009) y las sucesivas Directivas que desde ese año se han venido produciendo sobre condiciones de entrada y salida, residencia, solicitud de permiso de trabajo, reagrupación familiar e integración (Directiva 2009/50/CE; Directiva 2009/52/CE; Directiva 2011/98/UE; Directiva 2013/151/COM; y Directiva 2014/36/UE).

En la actualidad, las tragedias de Lampedusa y los crecientes problemas en Ceuta y Melilla han puesto en alerta a la Unión Europea, quién a través de su Consejo Europeo y el FRONTEX (gestión de fronteras exteriores) declaran la necesidad de incidir en la solidaridad y cooperación con los países de origen de estos inmigrantes. Pero a pesar de estas encomiables declaraciones de intenciones la Unión Europea no ha ofrecido hasta la fecha soluciones a la cruda realidad que nos ofrecen los medios de comunicación sobre la inmigración ilegal. A ello sin duda contribuye el papel que estos juegan en la interpretación que los ciudadanos hacen la misma, pero también pone en tela de juicio el papel de los gobiernos europeos y de los representantes políticos comunitarios de los países miembros, en la búsqueda de una solución al drama de la inmigración ilegal. 


\section{LOS PARTIDOS POLÍTICOS Y LA POLITIZACIÓN DE LA INMIGRACIÓN}

La politización de la inmigración en nuestro país y en el resto de Europa obedece a la interacción y participación de los agentes sociales y políticos, en un contexto en el que los medios de comunicación dan visibilidad a una realidad que tiene innumerables matices (Morales Laura y Ros Virginia, 2012:4). Suele ser presentada como un problema, desde la perspectiva de un mercado laboral en recesión económica, con los conflictos que plantea la integración de los inmigrantes o el excesivo número de ciudadanos no nacionales en la utilización de servicios públicos. Pero también puede ofrecer un enfoque amable de la inmigración, incidiendo en su contribución económica a las arcas del Estado a través de los impuestos, o en la presentación de movimientos sociales y ONGs asistenciales desde la faceta humanitaria.

Pero, de entre todos los agentes implicados en el fenómeno de la inmigración, son los partidos políticos y las instituciones del Estado los que centralizan el debate, siendo por tanto la politización un juego, en el que el protagonismo de estos es canalizado a través de los medios de comunicación, mostrando una única realidad migratoria para la mayoría de la ciudadanía. El papel de estos últimos en la politización de la inmigración es más que evidente, aunque se aleja del objetivo de este estudio. Por ello, analizaremos el rol que los partidos políticos y las instituciones del Estado, en especial el Parlamento y sus grupos parlamentarios, juegan en las políticas migratorias actuales.

En el escenario actual, la inmigración es percibida por los ciudadanos como un peligro, tal y como se desprende de las encuestas que el Centro de Investigaciones Sociológicas (CIS. Estudio $\mathrm{n}^{\circ}$ 2967. Octubre 2012) realiza. Ha estado situada, a lo largo de la última década como el cuarto o quinto problema para los ciudadanos, aunque si bien es cierto que desde el año 2007 (crisis económica) la preocupación de los españoles por esta cuestión ha sido menor, pero no lo ha sido la valoración negativa de la misma (Zapata Barrero, 2008:107). Y nuestros partidos políticos y grupos parlamentarios han considerado la cuestión como prioritaria en sus agendas políticas y electorales. Es decir, la inmigración ha sido un tema central en los debates y en la implementación de políticas en el ámbito nacional, autonómico, provincial y local. Pero, ¿está realmente la inmigración en los programas electorales de los partidos políticos? ¿Ofrecen los partidos soluciones al problema que ésta genera? ¿Obedecen las políticas legislativas a contextos socioeconómicos concretos, a sucesos trágicos de entrada de inmigrantes ilegales, a problemas de integración en la sociedad de acogida, o a la delincuencia? En definitiva, ¿existen políticas correctas en materia de inmigración?

A este respecto, establecemos como presunción que los flujos migratorios, las diferencias culturales entre la población inmigrante y la autóctona, la bonanza económica y una baja tasa de paro, así como la aparición de los inmigrantes y colectivos de defensa de los intereses de los mismos en la escena social, favorece la politización de del fenómeno. O para ser más exactos, aumenta la politización en períodos de crisis humanitarias y de fronteras $(2000$ a 2006), mientras que se reduce la misma en momentos en los que la crisis económica y el paro se convierten en la cuestión central del debate político (2008 a 2014).

En la práctica, son las intervenciones de los grupos parlamentarios en las Cortes Generales, como consecuencia de las preguntas orales en interpelaciones circunscritas dentro de la función del control de la actividad del Gobierno, o la propia actividad legislativa, las que suelen centrar el debate público sobre la inmigración. El debate se origina como consecuencia de sucesos trágicos, de los que los medios de comunicación se hacen eco, como son la llegada "masiva" de inmigrantes irregulares a nuestras costas, salto de frontera, o disturbios en determinados lugares de concentración de inmigrantes. Pero también cuando la 
noticia tiene su referencia en los procesos de regularización o en los problemas que genera la integración de los inmigrantes.

El Congreso de los Diputados se convierte en fuente productora de discurso sobre la inmigración (Zapata Barrero, 2008:35), ya que son los grupos parlamentarios, los que siguiendo las directrices de los partidos políticos a los que pertenecen, muestran con sus intervenciones su visión sobre la inmigración. No obstante, cierto es que esa postura suele ser presentarse en la mayoría de las ocasiones a través de las preguntas e interpelaciones, como sucedió y está sucediendo durante la VI, VII, VIII y XIX (la presente) legislatura. La incidencia de este debate en la función legislativa es menor, y ello es debido a que los partidos políticos y grupos parlamentarios son conscientes de la visibilidad que tienen sus intervenciones en sede parlamentaria a través de los medios de comunicación. Por ello, podemos afirmar que la inmigración entra de lleno en el debate social a través del Parlamento, pero con un matiz que ha de ser tenido en cuenta: la visión del ciudadano a través de los medios de comunicación presenta un debate en torno a la inmigración con tintes negativos. A nuestro juicio, la ciudadanía percibe confrontación, conflicto y crítica, pero sin entrar en el fondo de la cuestión. Y ello es debido a la razón antes apuntada. Los agentes políticos son conscientes de la repercusión de ese debate, por lo que enfoque sobre la inmigración y los problemas que conlleva están altamente condicionados electoralmente. $\mathrm{O}$ lo que es los mismo, tienen en cuenta más a su electorado y las consecuencias que pueden tener sus declaraciones sobre las próximas elecciones que el problema en sí mismo. A modo de ejemplo puede observarse esta realidad en los recientes sucesos sobre las concertinas en la valla de Melilla (2014), o los debates recientes en ayuntamientos (Vitoria 2014) relacionados con la inmigración y determinadas contingencias de la misma.

Pero si el debate parlamentario centra en buena medida el debate de la agenda política española, no es menos cierto que debe ser el programa electoral el que ofrezca respuestas a las preguntas planteadas por la ciudadanía. Se convierte en el elemento básico sobre el que el partido político refleja sus ideas y aporta soluciones a los problemas que la ciudadanía tiene vertebrado sobre la ideología del partido-, convirtiéndose en un compromiso con sus electores, que en teoría debería reproducir en el Gobierno, si tienen oportunidad de ejercer el poder.

Partimos en el presente trabajo, de la observación y estudio de los programas electorales de las últimas elecciones generales (noviembre del 2011) y europeas (mayo 2014) de los principales partidos políticos con representación parlamentaria (en el ámbito del Parlamento español y europeo). Acotar el estudio a estos años y sólo a los partidos de ámbito nacional, nos permite tener una visión más cercana de las posiciones políticas en torno a la inmigración, sobre todo teniendo en cuenta que en España todavía no se ha consolidado ningún partido antiinmigración, como sí ha sucedido en otros países europeos (Austria, Bélgica, Francia, Italia, Noruega o Suiza, entre otros).

Así las cosas, consideramos que pueden clasificarse las ideas sobre inmigración en torno a la clásica distinción derecha-izquierda. No obstante, hay que dejar claro que esta distinción se difumina en contextos en los que la inmigración no es percibida como un peligro, es decir, en situaciones de crisis económica o ausencia de conflictos en las fronteras. Lo que refleja el puro utilitarismo de la cuestión en función del contexto socio-económico, y muestra el escaso interés de los partidos políticos por la inmigración.

Para los partidos conservadores -en este caso tomamos como referencia al Partido Popular- la inmigración aparece en el programa electoral del 2011 (apartado 3.6. Integración: mismos derechos, mismas obligaciones) en torno a tres ideas básicas: la primera incide en 
que España se convirtió en el primer destino de la inmigración en la Unión Europea, rejuveneciendo la población y contribuyendo a la prosperidad económica; otra conecta la idea de una inmigración legal y ordenada con el mercado de trabajo desde una perspectiva comunitaria; y la última vertebra la inmigración en el término integración desde el empleo. En definitiva, un programa electoral que en apenas dos páginas desarrolla la cuestión de la inmigración en un modelo: inmigración cualificada vinculada al empleo.

En el programa electoral a las elecciones europeas la referencia a la inmigración es puramente residual, incidiendo en la idea de una inmigración regular y ordenada en una Europa más abierta y solidaria.

En lo que se refiere a los partidos progresistas -Partido Socialista Obrero Español e Izquierda Unida- el primero recoge en su programa electoral del 2011 (apartado 7.2.4 Integrar la diferencia: políticas de inmigración) la inmigración con un desarrollo parecido al del Partido Popular (integración, control de los flujos migratorios, e inmigración asociada a mercado de trabajo), pero con diecisiete propuestas concretas. A simple vista parecen muchas propuestas, pero a nuestro juicio, merecerían una mayor concreción. Destacan entre otras, la integración fundamentada en la escuela, empresa y barrio; las política para evitar la exclusión social de los inmigrantes; la diversidad en la escuela; un desarrollo urbanístico inclusivo que evite la segregación y los guetos; protocolos de actuación en los centros educativos para acabar con el racismo y la xenofobia; igualdad de derechos entre los españoles y extranjeros; control fronterizo en colaboración con el FRONTEX; y el fomento de la cooperación al desarrollo. En su programa electoral a las elecciones europeas de 2014 se pronuncian en parecido sentido, con especial referencia a la colaboración con los países de los que provienen los inmigrantes, pero sin propuestas concretas.

Izquierda Unida por su parte, desarrolla la inmigración en el programa electoral de 2011 fundamentándolo en los siguientes principios generales: el respeto y la aplicación de los tratados internacionales de derechos humanos en la lucha contra el racismo y la xenofobia (citando los principales Convenios y Declaraciones al respecto); modificación legislativa en materia de extranjería y asilo con medidas concretas (eliminación de la sanción de expulsión por estancia irregular, el Cierre de los Centros de Internamiento para Extranjeros, reforma del Código Civil en materia de nacionalidad, y creación de una Ley integral para la igualdad de trato y la no discriminación); reforzar los instrumentos contra la explotación laboral y la trata de seres humanos, así como los medios materiales en la educación y en la sanidad. En el programa electoral europeo de 2014 desarrollan un programa similar, con un denominador común: la apertura de fronteras en aras de la libre circulación de personas, siendo sancionados los países que teniendo acuerdos con la Unión Europea, limitan la libre circulación.

Por último, hemos decidido incorporar otro partido de ámbito nacional con representación parlamentaria en las últimas elecciones generales, que se encuentra a medio camino en la dicotomía izquierda-derecha. Unión Progreso y Democracia, entendido como partido de centro izquierda en lo social y como partido de centro derecha en lo nacional. En el programa electoral de 2011 (apartado 5.5) otorga especial importancia a la competencia comunitaria en materia de inmigración sincronizando las diferentes legislaciones nacionales; expresa la necesidad de luchar contra las mafias de inmigración ilegal endureciendo las penas; propone la creación de un Servicio Nacional de los Inmigrantes en materia de permisos de residencia y trabajo; la revisión de la Ley de Extranjería con el objetivo de mejorar el trato de los inmigrantes extracomunitarios; y acabar con el carácter penitenciario ilegal de los Centros de Internamiento. En el reciente programa electoral a las elecciones europeas (apartado 2.3.3) reitera la necesidad de una política europea común de inmigración. 
Del estudio de estos cuatro programas electorales, no puede afirmarse que las diferencias apriorísticas entre la derecha e izquierda están contenidas en los mismos. De hecho, consideramos que la diferencia entre unos y otros obedece más a la existencia de un bipartidismo imperfecto en España. Los dos grandes partidos (PP y PSOE) que se han ido alternado en el poder desde que nuestro país es una democracia, exponen sus ideas sobre la inmigración con carácter genérico y sin propuestas concretas, valorando positivamente el papel de la UE, de la agencia FRONTEX, y solicitando la colaboración con los países de origen para mejorar la integración de los inmigrantes. Llama poderosamente la atención que ambos partidos apelen a la UE como solución al problema de la inmigración, otorgando a la misma en sus respectivos programas a las recientes elecciones europeas un papel residual. Por el contrario, resulta al menos curioso, que partidos con representación minoritaria en unas elecciones generales (en las elecciones del 2011, IU obtuvo 11 escaños y UPyD 5) consideren que la inmigración requiere políticas distintas, siendo muy críticos con la política migratoria europea actual (IU), no fundamentada en el respeto de los derechos humanos y en el respeto del Derecho Internacional. Exigen por tanto, un cambio en ese sentido.

En resumidas cuentas, los cuatro programas electorales anteriormente analizados, arrojan luz sobre la politización del fenómeno de la inmigración en nuestro país. Los dos grandes partidos (PP y PSOE) con opciones de gobernar prefieren considerar la inmigración como una cuestión secundaria en sus programas electorales. Creen que en un contexto de crisis económica, con una tasa de paro alta y con inmigrantes volviendo a su país de origen, la inmigración pasa a ser algo de lo que no hace falta ocuparse. Con una declaración de intenciones genérica les basta. Consideran que en materia de inmigración no existe un problema hasta que los medios de comunicación lo evidencian, y la noticia es utilizada en clave electoral por la oposición política. Pero en el lado opuesto, dos programas electorales de partidos pequeños -si me permiten la expresión- desarrollan políticas migratorias y propuestas legislativas más amplias.

Llegados a este punto, parece necesario concretar qué elemento es el que incide en mayor medida en la más que evidente politización de la inmigración. Resulta más que obvio, que en los programas electorales la cuestión de la inmigración, al menos en los dos grandes partidos, no es un asunto prioritario. Sí que ocupa un lugar significativo en los programas de los partidos minoritarios. Y es así por dos razones: la primera tiene que ver con la importancia que la ciudadanía otorga a los programas electorales. Ésta, según la politología y los diversos estudios de las ciencias sociales, es mínima a la hora de otorgar el voto a un partido u otro. Razón por la cual los partidos políticos tienen programas muy genéricos y poco concretos. Y la segunda, cuanto más concreción y existencia de propuestas, mayor es la responsabilidad a la hora de cumplirlas.

Por lo tanto, la politización de la inmigración se produce en la mayoría de los casos cuando los medios de comunicación visibilizan situaciones que ponen en tela de juicio la labor de los partidos políticos. Éstos (y los grupos parlamentarios) junto con las instituciones públicas, se sienten compelidos a iniciar un debate del que puedan obtener réditos electorales o a desarrollar políticas legislativas que calmen los ánimos de los ciudadanos ante imágenes de entrada masiva de inmigrantes en la frontera, conflictos culturales o religiosos (velo), la existencia de guetos o la delincuencia. En resumidas cuentas, políticas de inmigración al albur de trágicos acontecimientos y no verdaderas políticas fruto del análisis y estudio sosegado de los verdaderos problemas que plantea, que deben tener como soporte fundamental, el reconocimiento y respeto de los derechos humanos. 


\section{CONCLUSIONES}

A lo largo de los últimos veinte años, la inmigración en nuestro país ha alcanzado niveles que sitúan a nuestro país como uno de los referentes en esta materia y lo han convertido en un país de tránsito y receptor de inmigrantes.

Las respuestas a esta novedosa situación en materia legislativa han fluctuado desde el reconocimiento de derechos a los inmigrantes hasta la restricción de los mismos, con las consiguientes correcciones introducidas por nuestro Tribunal Constitucional Éstas políticas legislativas han tenido lugar en el ámbito europeo y nacional, y ponen de manifiesto la necesidad de coordinación entre los países miembros, cuyo horizonte debe ser el de una política común europea en la que el respeto de los derechos fundamentales sea el eje central de la misma. Pero también la existencia de políticas en el marco de la cooperación con los países de origen.

Por ello, se ha procedido a analizar qué papel juegan los partidos políticos y sus programas electorales en la visión que de la inmigración tienen los ciudadanos. Consideramos que la politización de la inmigración tiene su origen en la imagen que los medios de comunicación proyectan, y de la que los partidos políticos y sus grupos parlamentarios defienden o critican en el Congreso. Ante un suceso trágico, la inmigración se politiza por estos agentes políticos, con un objetivo claro: el electorado.

Y en nuestro país, pese a la casi nula existencia de partidos antiinmigración, los partidos políticos de ámbito nacional analizados, no ofrecen soluciones plausibles a los problemas que la inmigración plantea. Sus políticas suelen girar en torna a una idea: el mercado laboral. $\mathrm{Si}$ éste está en plena expansión y la bonanza económica lo permite, se amplía la entrada de inmigrantes en nuestro país. Si no es así, se limita. Del análisis de sus programas electorales, llegamos a esa conclusión, en especial en lo que se refiere a nuestros dos grandes partidos.

En definitiva, una concepción limitada de la inmigración, únicamente vinculada al mercado de trabajo, con cierre de fronteras en Europa, y con campañas de los medios de comunicación alertando sobre la amenaza de la llegada masiva de inmigrantes a nuestro país. Una política de inmigración, a nuestro juicio, desacertada.

\section{BIBLIOGRAFÍA}

ÁLVAREZ CONDE, E. y TUR AUSINA, R. (2012). Derecho Constitucional. Madrid: Tecnos. MARTÍNEZ DE PISÓN, J. (2004). "La (no) política de inmigración y el Estado de Derecho". Cuadernos Electrónicos de Filosofía del Derecho, $\mathrm{n}^{\circ}$ 10/2004.

MORALES, L. y ROS, V. (2012). La politización de la inmigración en España en retrospectiva comparada. Documentos CIDOB. Migraciones $\mathrm{n}^{\circ} 25$. Barcelona: Centre for International Affairs.

ORTEGA GIMÉNEZ, A. y LÓPEZ ÁLVAREZ, A. (coords). (2011). Cuestiones socio-jurídicas actuales sobre la inmigración y la integración de personas inmigrantes en España. Navarra: Civitas. Thomson Reuters.

ZAPATA-BARRERO, R.; GONZÁLEZ, E. y SÁNCHEZ MONTIJANO, E. (2008). El discurso político en torno a la inmigración en España y en la Unión Europea. Madrid: Documentos del Observatorio Permanente de la Inmigración. Ministerio de Trabajo en Inmigración.

ENLACES WEB:

www.cis.es. Centro de investigaciones sociológicas. Catálogo de encuestas. Actitudes hacia la inmigración (VI). Estudio no 2967. Octubre 2012.

www.ine.es. Instituto Nacional de Estadística. Demografía y población. 
www.mtin.es. Ministerio de trabajo e inmigración.

www.izquierda-unida.es. Izquierda Unida.

www.psoe.es. Partido Socialista Obrero Español.

www.pp.es. Partido Popular.

www.upyd.es. Unión Progreso y Democracia.

\section{Breve currículo:}

\section{Antonio López Álvarez}

Doctor en Derecho por la Universidad San Pablo CEU (sobresaliente "cum laudem" por unanimidad), Diplomado en Derecho Constitucional y Ciencia Política por el Centro de Estudios Políticos y Constitucionales, y Profesor de Derecho Constitucional desde el año 1996 en la misma Universidad. También ha cursado con éxito el Máster en Dirección de Recursos Humanos-Executive, en la Escuela de Negocios San Pablo CEU. Profesor de Derecho Constitucional del CEU-Universidad Cardenal Herrera en Elche, Coautor de la monografía sobre La inmigración en la Comunidad Valenciana: un estudio multidisciplinar, y coordinador y autor, entre otras, de la obras Guía práctica de los derechos y libertades de los extranjeros y su integración social en la ciudad de Elche, Glosario Jurídico Básico, o Casos Prácticos para el Grado en Derecho. 